Research Paper

\title{
Cancer antigen profiling for malignant pleural mesothelioma immunotherapy: expression and coexpression of mesothelin, cancer antigen 125, and Wilms tumor 1
}

\author{
Takashi Eguchi'1,2, Kyuichi Kadota ${ }^{1,3,4}$, Marissa Mayor ${ }^{1}$, Marjorie G. Zauderer ${ }^{5}$, \\ Andreas Rimner 6 , Valerie W. Rusch ${ }^{1}$, William D. Travis ${ }^{3}$, Michel Sadelain ${ }^{7}$ and \\ Prasad S. Adusumilli, 1,7 \\ ${ }^{1}$ Thoracic Service, Department of Surgery, Memorial Sloan Kettering Cancer Center, New York, NY, USA \\ ${ }^{2}$ Division of Thoracic Surgery, Department of Surgery, Shinshu University School of Medicine, Matsumoto, Japan \\ ${ }^{3}$ Department of Pathology, Memorial Sloan Kettering Cancer Center, New York, NY, USA \\ ${ }^{4}$ Department of Diagnostic Pathology, Faculty of Medicine, Kagawa University, Kagawa, Japan \\ ${ }^{5}$ Thoracic Oncology Service, Division of Solid Tumor Oncology, Department of Medicine, Memorial Sloan Kettering Cancer \\ Center, New York, NY, USA \\ ${ }^{6}$ Department of Radiation Oncology, Memorial Sloan Kettering Cancer Center, New York, NY, USA \\ ${ }^{7}$ Center for Cell Engineering, Memorial Sloan Kettering Cancer Center, New York, NY, USA \\ Correspondence to: Prasad S. Adusumilli, email: adusumip@mskcc.org \\ Keywords: mesothelin, CA125, WT1, mesothelioma, chimeric antigen receptor \\ Received: May 10, $2017 \quad$ Accepted: August 15, $2017 \quad$ Published: September 12, 2017 \\ Copyright: Eguchi et al. This is an open-access article distributed under the terms of the Creative Commons Attribution License \\ 3.0 (CC BY 3.0), which permits unrestricted use, distribution, and reproduction in any medium, provided the original author and \\ source are credited.
}

\section{ABSTRACT}

Background: To develop cancer antigen-targeted immunotherapeutic strategies for malignant pleural mesothelioma (MPM), we investigated the individual and coexpressions of the cancer-associated antigens mesothelin (MSLN), cancer antigen 125 (CA125), and Wilms tumor 1 (WT1) in both epithelioid and non-epithelioid MPM.

Methods: All available hematoxylin and eosin-stained slides from patients who were diagnosed with MPM (1989-2010) were reviewed. We constructed tissue microarrays from 283 patients (epithelioid $=234$; non-epithelioid $=49$ ). Intensity and distribution for each antigen were assessed by immunohistochemistry.

Results: Positive expression of MSLN, CA125, and WT1 were demonstrated in 93\%, 75\%, and $97 \%$ of epithelioid MPM cases, and $57 \%$, 33\%, and $98 \%$ of nonepithelioid MPM cases, respectively. Triple- and double-positive antigen coexpressions were demonstrated in $72 \%$ and $23 \%$ of epithelioid MPM cases and $29 \%$ and $33 \%$ of non-epithelioid MPM cases, respectively. Complete absence of expression for all three antigens was demonstrated in $<2 \%$ of MPM cases. More than two-thirds of MPM cases had $\geq 50 \%$ distribution of MSLN-positive cells and, among the remaining third, half had $\geq 50 \%$ distribution of WT1-positive cells. CA125/MSLN coexpression was observed in more than two-thirds of epithelioid MPM cases and one-third of nonepithelioid MPM cases.

Conclusion: A limited number of cancer-associated antigens can target almost all MPM tumors for immunotherapy. 


\section{INTRODUCTION}

Malignant pleural mesothelioma (MPM) is an aggressive malignancy with a median survival of 9 to 12 months [1]. Although multimodality clinical trials for early-stage MPM have shown encouraging results [2-6], its benefits are limited [7,8]. Additionally, considering that the majority of patients are diagnosed at a late stage, multimodality therapy, including surgical resection, is only an option for select patients [9].

For other thoracic malignancies, such as lung cancer, variable driver mutations have been discovered and corresponding targeted molecular agents have been applied in clinical practice. Recent comprehensive genomic analysis of transcriptomes and exomes from patient MPM samples have identified significantly mutated genes, recurrent mutations, gene fusions, and splicing alterations [10]. However, there is currently no clinically accepted targeted molecular therapy for MPM even though multiple clinical and preclinical studies have attempted to target recently discovered molecular alterations and gene overexpressions [11].

Despite poor prognosis for patients with MPM, tumor-infiltrating immune cells have been investigated and have been shown to be prognostic indicators [1215]. Recent immunotherapeutic strategies against MPM have demonstrated the immunogenicity of MPM [16] and further suggest that promotion of antigen-specific T-cell responses may prove beneficial. Adoptive T-cell therapy is an immunotherapeutic strategy that includes chimeric antigen receptor (CAR) T-cell therapy [17] and T-cell receptor (TCR) therapy. These therapies utilize genetic engineering to target a patient's own $\mathrm{T}$ cells to a tumorassociated antigen. Although results from antigen-targeted cellular immunotherapy studies have shown promise in treating hematologic malignancies [18], candidate target antigens for solid tumors, such as MPM, are limited. Unlike CD19 in leukemia and lymphomas, there is no single antigen present on all tumor cells. Even when an antigen is expressed in the majority of cells, the expression intensity and distribution are not uniform and this may allow antigen escape of low-antigen expressing cells. Strategies that target two cancer-associated antigens have been advantageous [19] and coexpression and distribution of antigens are very important to the further development of dual-antigen targeting strategies. During our search for candidate antigens, we investigated the overexpression of the cell-surface glycoproteins mesothelin (MSLN) and cancer antigen 125 (CA125; also known as mucin-16 [MUC16]), and the transcription factor Wilms tumor 1 (WT1).

MSLN is overexpressed in a broad spectrum of solid tumors including mesothelioma and lung cancer [20-24]. Our rationale for targeting MSLN in MPM is based on our published observations that have shown that: (1) MSLN promotes MPM cell invasion and matrix metalloprotease secretion; (2) MSLN is overexpressed in $>90 \%$ of patients with epithelioid MPM [23]; and (3) MSLN-targeted CAR T cells delivered regionally to eradicate MSLN-positive pleural tumors align with the regionally aggressive biology of MPM [17]. Supported by this rationale, we are conducting a Phase I clinical trial (NCT02414269) to evaluate the safety of regionally administered MSLN-targeted CAR T cells in patients with either primary pleural malignancies (MPM) or secondary pleural malignancies (lung and breast cancers) with MSLN expression. Other investigators have been conducting MSLN-targeted CAR T-cell therapy clinical trials with systemic administration of CAR T cells (NCT01583686, NCT02159716, NCT01355965, and NCT02930993). In order to expand our immunotherapeutic approaches to treating non-epithelioid, MSLN-negative, and MSLNfocally positive MPM, identifying alternative or additional antigens to target is necessary. Neither overexpression of other cancer-associated antigens nor correlative expressions between those antigens and MSLN have been fully investigated.

CA125 overexpression was initially recognized in ovarian cancer and has recently been reported in several other cancers such as pancreatic [25] and lung cancer $[26,27]$. Prior studies have suggested that CA125 may facilitate peritoneal metastasis via binding to MSLN in ovarian cancer $[28,29]$ and the CA125-MSLN interaction is associated with increased invasion and worse prognosis in pancreatic cancer [30,31]. Published evidence supports the notion that MSLN- and CA125-specific immune responses are beneficial [32-34] and that promising preclinical and ongoing early-phase clinical studies have demonstrated that MSLN and CA125 may be effective cancer antigens to target with immunotherapy for solid tumors [35-37]; however, the frequency and distribution of CA125 and MSLN co-expression in MPM have not been previously studied.

WT1 is a nuclear protein that is involved in tumor growth and overexpressed in multiple malignancies [38, 39]. Since WT1 is highly overexpressed in MPM, while its expression in lung adenocarcinoma is exclusively low, pathologists currently routinely use immunohistochemical (IHC) expression of WT1 for pathologic diagnosis of MPM [40]. Although WT1 is located in the nucleus, it can present on the cell surface with MHC molecules [38]. WT1 peptide vaccination for the treatment of MPM has yielded T-cell immune responses [41, 42]. Gene-modified WT1 TCR therapy is currently being studied in clinical trials (NCT02550535 and NCT01621724).

To develop personalized immunotherapeutic strategies for the treatment of MPM, we aimed to investigate the individual and coexpressions of MSLN, CA125, and WT1 in both epithelioid and non-epithelioid MPM. Heterogeneity of cancer-associated antigen expression in solid tumors allows for therapy resistance via antigen escape and is a known challenge for immunotherapies 
[43-45]. In anticipation of this challenge, we conducted a detailed analysis of the distribution of antigen-positive cells in each patient tumor for each cancer-associated antigen.

\section{RESULTS}

\section{Clinicopathologic and demographic characteristics of patients}

Among all 283 patients, 234 patients were diagnosed with epithelioid mesothelioma, 26 with biphasic mesothelioma, and 23 with sarcomatoid mesothelioma. Of the 234 patients with epithelioid mesothelioma, 39 patients were classified as having pleomorphic mesothelioma. The median age of patients with epithelioid mesothelioma and non-epithelioid mesothelioma (biphasic or sarcomatoid) were 63 years (range, 29-85 years) and 66 years (range, 41-79 years), respectively. The majority of patients were male $(73 \%$ and $88 \%$ for epithelioid and non-epithelioid mesothelioma, respectively), positive for asbestos exposure ( $42 \%$ and $53 \%$ ), smokers ( $58 \%$ and $57 \%$ ), never received induction chemotherapy before surgery $(70 \%$ and $80 \%)$, and were diagnosed with late-stage disease (stage III/IV, 68\% and 84\%) (Table 1).

\section{Intensity and distribution of antigen expression}

Evaluation of MSLN, CA125, and WT1 were completed for 230 (98\%), 226 (97\%), and 226 (97\%) cases of epithelioid MPM, respectively. For non-epithelioid MPM patients, evaluation of all 3 antigens was completed for $49(100 \%)$ cases. Among epithelioid MPM cases, MSLN expression was positive in $93 \%$, CA125 expression was positive in $75 \%$, and WT1 was positive in $97 \%$ of cases. Distribution $\geq 50 \%$ of MSLN-, CA125-, and WT1-positive tumor cells were observed in $84 \%, 20 \%$, and $72 \%$ of epithelioid MPM cases, respectively. Antigen expression intensity was: (1) strong in 35\% and moderate in $34 \%$ of cases for MSLN expression; (2) strong in 9\% and moderate in $27 \%$ of cases for CA125 expression; and (3) strong in $31 \%$ and moderate in $43 \%$ of cases for WT1 expression (Table 2). For non-epithelioid MPM cases, MSLN expression was positive in $57 \%$, CA125 expression was positive in 33\%, and WT1 expression was positive in $98 \%$ of cases. Distribution $\geq 50 \%$ of MSLN-, CA125-, and WT1-positive tumor cells were observed in $25 \%, 6 \%$, and $45 \%$ of non-epithelioid MPM cases, respectively. Antigen expression intensity was: (1) strong in $8 \%$ and moderate in $16 \%$ of cases for MSLN expression; (2) strong in $0 \%$ and moderate in $4 \%$ of cases for CA125 expression; and (3) strong in $22 \%$ and moderate in $37 \%$ of cases for WT1 expression (Table 2).

\section{Coexpression of MSLN, CA125, and WT1}

Concurrent evaluation of 3 antigens was completed for $220(94 \%)$ epithelioid MPM cases and 49 (100\%) non-epithelioid MPM cases. Triple antigen coexpression was demonstrated in $72 \%$ of epithelioid MPM cases and double antigen coexpression was demonstrated in $23 \%$ of epithelioid MPM cases. Triple and double antigen coexpressions were demonstrated in $29 \%$ and $33 \%$ of nonepithelioid MPMs, respectively. Only $1 \%$ of epithelioid and $2 \%$ of non-epithelioid MPM cases demonstrated complete absence of expression of any of the three antigens (Table 3).

\section{Coexpression of MSLN and CA125}

Expression of either MSLN or CA125 was demonstrated in $96 \%$ of epithelioid and $57 \%$ of nonepithelioid MPM cases. MSLN/CA125 coexpression was demonstrated in $73 \%$ of epithelioid and $29 \%$ of non-epithelioid MPM cases. Single antigen expression of MSLN was exhibited in $21 \%$ of epithelioid and $14 \%$ of non-epithelioid MPM cases, whereas single antigen expression of CA125 was exhibited in only $2 \%$ of epithelioid and $4 \%$ of non-epithelioid MPM cases (Table 4).

\section{Distribution of antigen-positive cells by histologic subtypes}

The comprehensive data analysis of the distribution of antigen positivity for each individual patient is pictographically represented in Figure 1. Figure 1 is a representative case of three IHC sections. One section demonstrates the mean distribution of the antigen for the patient and the resultant patient pie graph. The distribution of antigen-positive cells for each of the three antigens in each patient is represented in Figure 2. Each pie graph represents the calculated antigen distributions of a single patient.

The 269 pie graphs were categorized into 4 groupsnon-pleomorphic epithelioid, pleomorphic epithelioid, biphasic, and sarcomatoid. Given that our objective was to assess double and triple antigen coexpressions from the perspective of MSLN as the ideal antigen, we first sorted patients with MSLN-predominant tumors who were wellsuited for MSLN-targeted therapy (i.e., MSLN distribution $\geq 50 \%$ ). Subsequently, patients with MSLN distribution $<50 \%$ were sorted by WT1 distribution. The blue background represents patients whose tumors had $\geq 50 \%$ MSLN distribution and the green background represents patients whose tumors had both $<50 \%$ MSLN distribution and $\geq 50 \%$ WT1 distribution. Patients whose tumors had no antigen with $\geq 50 \%$ distribution have no background color associated with them.

For non-pleomorphic epithelioid MPM cases $(\mathrm{n}=$ $185), 161(87 \%)$ patients had $\geq 50 \%$ MSLN distribution and $18(10 \%)$ patients had $\geq 50 \%$ WT1 distribution without $\geq 50 \%$ MSLN distribution. For pleomorphic epithelioid MPM cases $(\mathrm{n}=35), 24(69 \%)$ patients had $\geq 50 \%$ MSLN distribution and 3 (9\%) patients had $\geq 50 \%$ 
Table 1: Malignant pleural mesothelioma patient characteristics

\begin{tabular}{|c|c|c|c|c|}
\hline \multirow{2}{*}{$\begin{array}{l}\text { Variables } \\
\text { Age (median, range) }\end{array}$} & \multicolumn{2}{|c|}{$\begin{array}{l}\text { Epithelioid } \\
\mathrm{n}=234(\%)\end{array}$} & \multicolumn{2}{|c|}{$\begin{array}{l}\text { Non-epithelioid* } \\
\text { n }=49(\%)\end{array}$} \\
\hline & \multicolumn{2}{|c|}{$63(29-85)$} & \multicolumn{2}{|c|}{$66(41-79)$} \\
\hline \multicolumn{5}{|l|}{ Gender } \\
\hline Female & 64 & $(27.4)$ & 6 & $(12.2)$ \\
\hline Male & 170 & $(72.6)$ & 43 & $(87.8)$ \\
\hline \multicolumn{5}{|l|}{ Asbestos exposure } \\
\hline$(+)$ & 97 & $(41.5)$ & 26 & $(53.1)$ \\
\hline$(-)$ & 70 & $(29.9)$ & 7 & $(14.3)$ \\
\hline Unknown & 67 & $(28.6)$ & 16 & $(32.7)$ \\
\hline \multicolumn{5}{|l|}{ Smoking history } \\
\hline$(+)$ & 136 & $(58.1)$ & 28 & $(57.1)$ \\
\hline$(-)$ & 46 & $(19.7)$ & 8 & $(16.3)$ \\
\hline Unknown & 52 & $(22.2)$ & 13 & $(26.5)$ \\
\hline \multicolumn{5}{|c|}{ Induction chemotherapy } \\
\hline$(+)$ & 65 & $(27.8)$ & 9 & $(18.4)$ \\
\hline$(-)$ & 164 & $(70.1)$ & 39 & $(79.6)$ \\
\hline Unknown & 5 & $(2.1)$ & 1 & (2.0) \\
\hline \multicolumn{5}{|l|}{ Stage } \\
\hline I, II & 76 & $(32.5)$ & 8 & $(16.3)$ \\
\hline III, IV & 158 & $(67.5)$ & 41 & $(83.7)$ \\
\hline
\end{tabular}

*Biphasic or sarcomatoid subtypes

$\mathrm{SD}$, standard deviation

WT1 distribution without $\geq 50 \%$ MSLN distribution. For biphasic MPM cases $(n=26), 9(35 \%)$ patients had $\geq 50 \%$ MSLN distribution and $8(31 \%)$ patients had $\geq 50 \%$ WT1 distribution without $\geq 50 \%$ MSLN distribution. For sarcomatoid MPM cases $(\mathrm{n}=23), 3(13 \%)$ patients had $\geq 50 \%$ MSLN distribution and $7(30 \%)$ patients had $\geq 50 \%$ WT1 distribution without $\geq 50 \%$ MSLN distribution. For all patients $(\mathrm{n}=269), 197(73 \%)$ patients $\mathrm{had} \geq 50 \%$ MSLN distribution and 36 (13\%) patients had $\geq 50 \% \mathrm{WT} 1$ distribution without $\geq 50 \%$ MSLN distribution.

\section{DISCUSSION}

In our study, we demonstrated that $>98 \%$ of epithelioid and non-epithelioid MPM cases had positive expression of at least one of the three cancer-associated antigens. Positive expression included strong antigen expression, high frequency of double and triple antigen expressions, and high distribution of antigen-positive tumor cells. These findings, combined with the survival benefits shown in MPM patients with MSLN-, CA125-, and WT1-specific immune responses, provide the rationale for the development of targeted therapies. Additionally, the expression of these three antigens on normal tissue is very low $[23,34,41]$ and this should be taken into consideration when developing new targeted therapies. Furthermore, published evidence has shown that antigen-specific spontaneous immune response are beneficial for different solid malignancies-MSLN in pancreatic cancer $[32,33]$, CA125 in ovarian cancer [34], and WT1 in mesothelioma [41] — and has driven us to explore the expression of these antigens on MPM. A growing number of immunotherapeutic investigations on the serial monitoring of these antigen-specific immune responses can further advance our understanding of immune responses and interactions for patients with MPM who have undergone treatment. The implications of intensity, distribution, and immune recognition of individual antigens should be kept in context when interpreting the antigen-specific immune responses.

Previous studies have reported that non-epithelioid subtypes were associated with worse prognosis compared with the epithelioid subtype in patients with MPM who were with surgery [46]. Additionally, we have reported 
Table 2: Distribution and intensity of cancer antigen expression in epithelioid and non-epithelioid malignant pleural mesothelioma

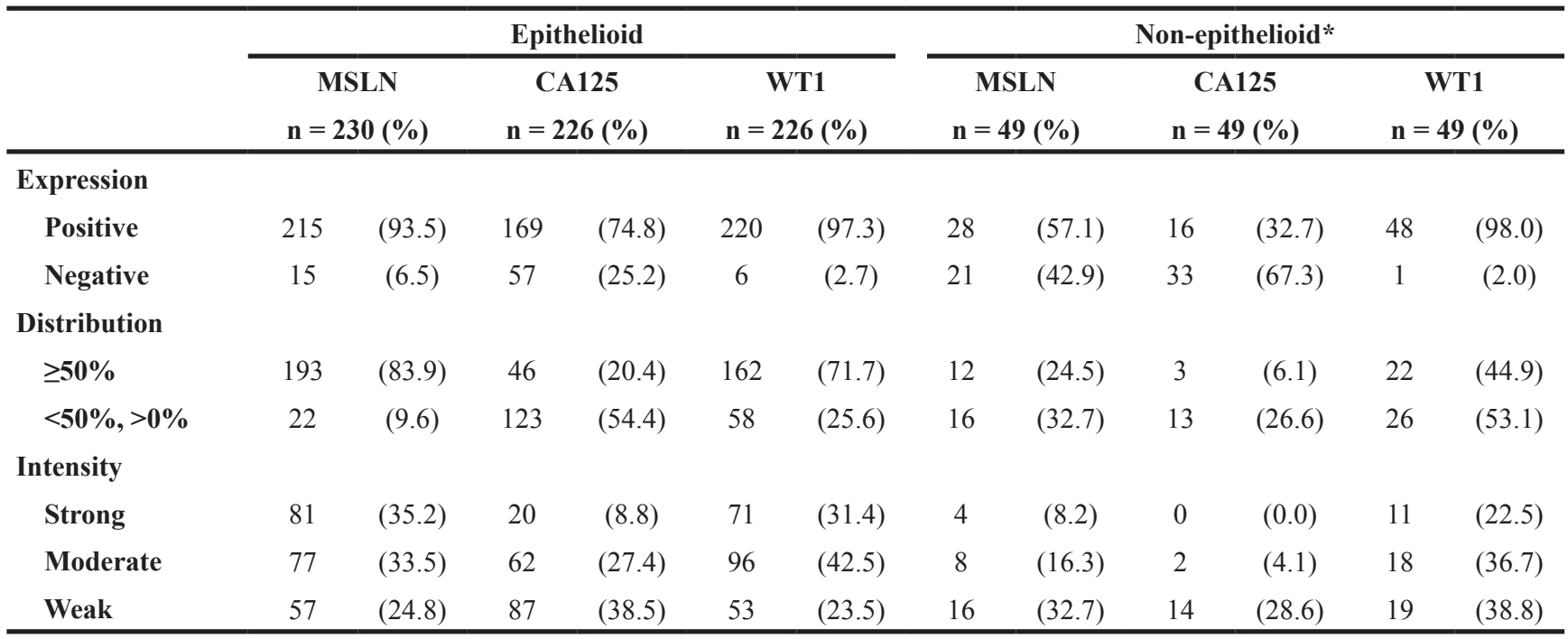

*Biphasic or sarcomatoid subtypes

CA125, cancer antigen 125; MSLN, mesothelin; WT1, Wilms tumor 1

Table 3: Coexpression of three cancer-associated antigens in epithelioid and non-epithelioid malignant pleural mesothelioma

\begin{tabular}{|c|c|c|c|c|}
\hline \multirow[b]{2}{*}{ Either antigen-positive } & \multicolumn{2}{|c|}{$\begin{array}{l}\text { Epithelioid } \\
n=220(\%)\end{array}$} & \multicolumn{2}{|c|}{$\begin{array}{l}\text { Non-epithelioid* } \\
\qquad n=49(\%)\end{array}$} \\
\hline & 218 & $(99.1)$ & 48 & $(98.0)$ \\
\hline Triple-positive & 158 & $(71.8)$ & 14 & $(28.6)$ \\
\hline Double-positive & 51 & $(23.2)$ & 16 & $(32.7)$ \\
\hline MSLN/CA125 & 3 & $(1.4)$ & 0 & $(0.0)$ \\
\hline MSLN/WT1 & 44 & $(20.0)$ & 14 & $(28.6)$ \\
\hline CA125/WT1 & 4 & $(1.8)$ & 2 & $(4.1)$ \\
\hline Single-positive & 9 & $(4.1)$ & 18 & $(36.7)$ \\
\hline MSLN & 1 & $(0.5)$ & 0 & $(0.0)$ \\
\hline CA125 & 0 & $(0.0)$ & 0 & $(0.0)$ \\
\hline WT1 & 8 & $(3.6)$ & 18 & $(36.7)$ \\
\hline Triple-negative & 2 & $(0.9)$ & 1 & $(2.0)$ \\
\hline
\end{tabular}

*Biphasic or sarcomatoid subtypes

CA125, cancer antigen 125; MSLN, mesothelin; WT1, Wilms tumor 1

that epithelioid MPM with pleomorphic features was associated with aggressive behavior and a similar survival rate to non-epithelioid MPM [47]. In our study, we investigated the individual and correlative expressions of three cancer-associated antigens, as well as their individual distribution in the tumor area, for each pathologic subtype. Interestingly, we found that these pathologic subtypes (non-pleomorphic epithelioid, pleomorphic epithelioid, biphasic, and sarcomatoid) had distinct antigen expression profiles, which are demonstrated by the proportion of patients with $\geq 50 \%$ distribution of each antigen. In non-pleomorphic epithelioid MPM, which is the most common MPM subtype, the majority of patients $(87 \%)$ had $\geq 50 \%$ MSLN-positive cell distribution. Patients with pleomorphic epithelioid MPM also had a high frequency (69\%) of $\geq 50 \%$ MSLN-positive cell distribution. Although the frequency of patients with $\geq 50 \%$ MSLN-positive cell distribution in non-epithelioid subtypes (biphasic, 35\%; 
Table 4: Coexpression of MSLN and CA125 in epithelioid and non-epithelioid malignant pleural mesothelioma

\begin{tabular}{lcccc}
\hline & \multicolumn{2}{c}{ Epithelioid } & \multicolumn{2}{c}{ Non-epithelioid* } \\
& \multicolumn{1}{c}{$\mathbf{n = 2 2 0}(\mathbf{\%})$} & $(73.2)$ & 14 & $\mathbf{n}=\mathbf{4 9}(\mathbf{\%})$ \\
\hline Both MSLN- and CA125-positive & 161 & $(20.5)$ & 14 & $(28.6)$ \\
Only MSLN-positive & 45 & $(1.8)$ & 2 & $(4.1)$ \\
Only CA125-positive & 4 & $(0.9)$ & 1 & $(2.0)$ \\
Both MSLN- and CA125-negative & 2 & & \\
\hline
\end{tabular}

*Biphasic or sarcomatoid subtypes

CA125, cancer antigen 125; MSLN, mesothelin

sarcomatoid, 13\%) was lower than those in epithelioid subtypes, nearly one-third of these subtypes (biphasic, $31 \%$; sarcomatoid, $30 \%$ ) had $\geq 50 \%$ WT1-positive cell distribution. This suggests that, in those patients with $\geq 50 \%$ WT1-positive cell distribution without $\geq 50 \%$ MSLN-positive cell distribution, WT1-targeted therapy may be an alternative treatment option to MSLN-targeted therapy.

The pathologic and prognostic role of CA125 in MPM has not been elucidated. Previous studies have suggested that there is an interaction between MSLN and
CA125 that may affect solid tumor metastatic potential [2831]. There is an ongoing, early-phase clinical trial that has yielded promising results with blocking the MSLN/CA125 interaction using a chimeric MSLN-targeted antibody in combination with platinum-based chemotherapy [35-37]. In our study, CA125 overexpression was almost exclusively observed in MSLN-positive MPM. Additionally, more than two-thirds of epithelioid and one-third of non-epithelioid MPMs had MSLN/CA125 coexpression. These findings further support our rationale to target MSLN and suggest the potential for development of a MSLN/CA125 dual-

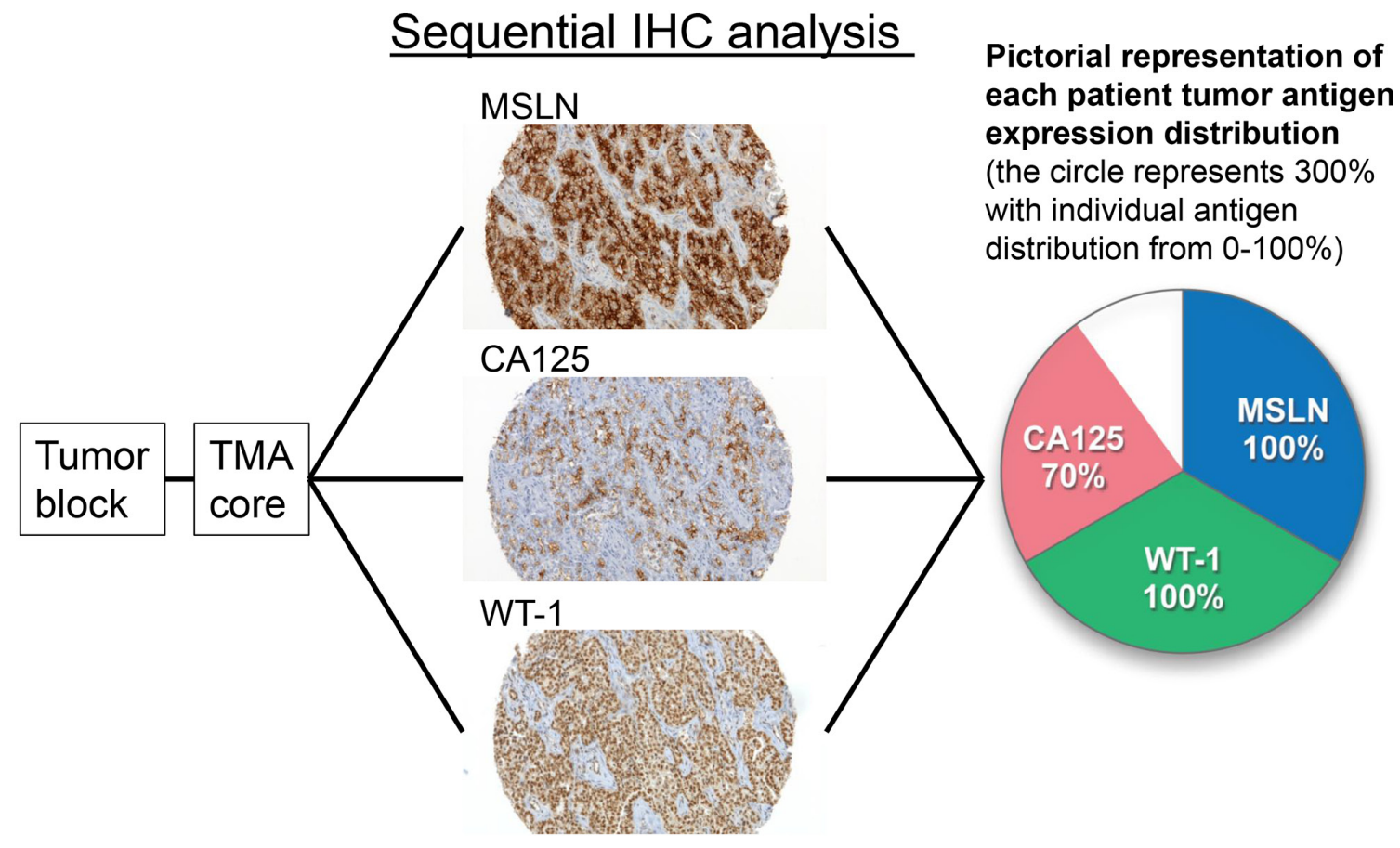

Figure 1: A representative case of sequential immunohistochemical analysis for distribution of antigen-positive cells. Immunohistochemical staining for mesothelin (MSLN), cancer antigen 125 (CA125), and Wilms tumor 1 (WT1) were performed using sequential sections of tissue microarray blocks. Distribution of antigen-positive cells among tumor areas in each core was evaluated. The distribution of MSLN was $100 \%$, CA125 was $70 \%$, and WT1 was $100 \%$. These values are shown in a pie graph for each patient. 
targeted therapy that augments the effect of MSLN-targeted therapy.

One limitation of our present study is the use of a tissue microarray (TMA) that may not identify tumors that are focally positive on whole-tissue block staining. Despite this, we selected six TMA cores from six different areas in each tumor. We think that the frequency of each antigen overexpression and the distribution of antigen-positive cells in each patient will not be significantly changed if a whole-tissue block were used to confirm these results.

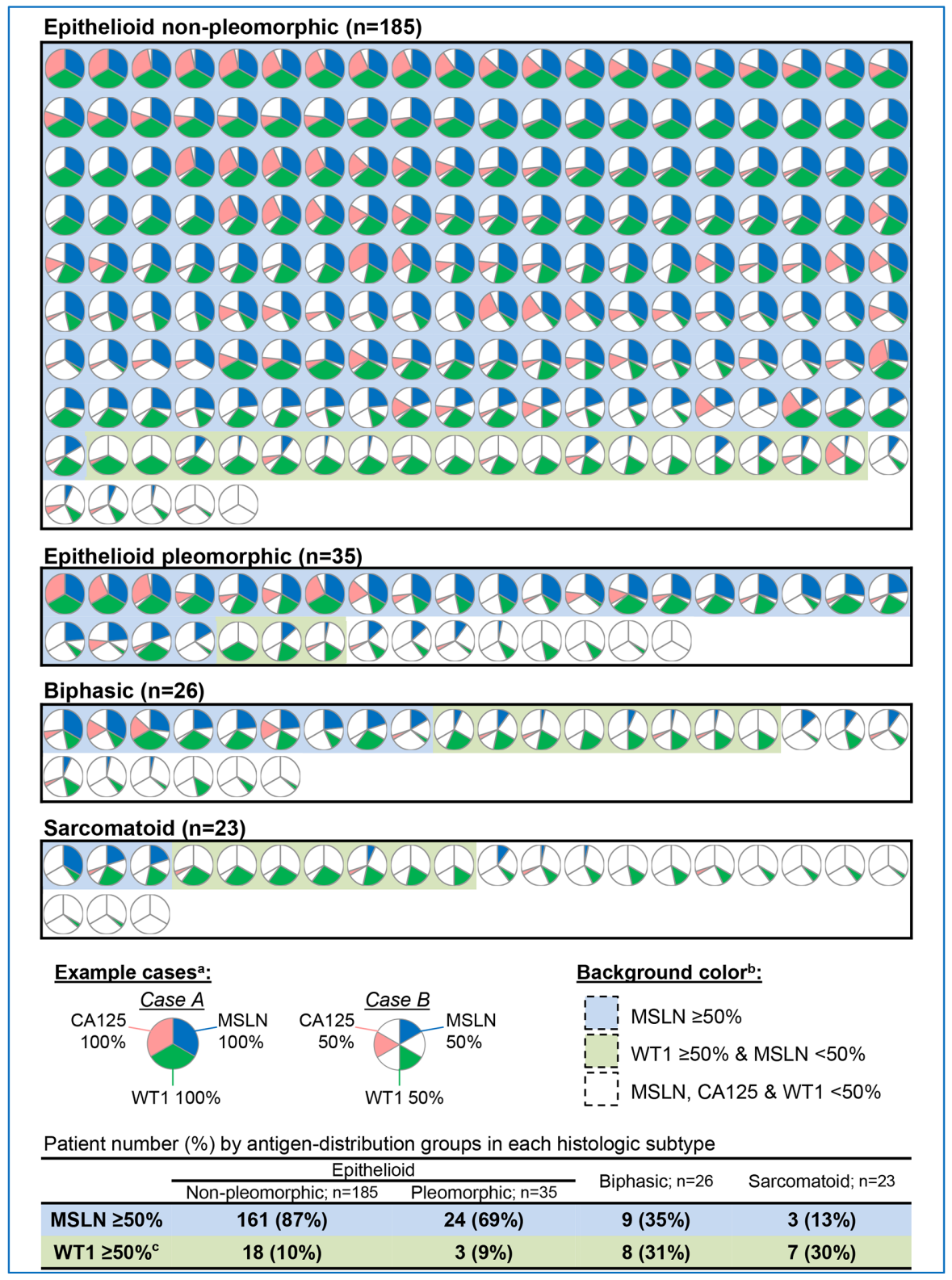

Figure 2: Antigen distribution pie graphs for each patient by histologic subtype. Distribution of antigen-positive cells in a tumor area for mesothelin (MSLN), cancer antigen 125 (CA125), and Wilms tumor 1 (WT1) were evaluated and shown in a pie graph for each patient. The blue background represents cases with $\geq 50 \%$ MSLN distribution and the green background represents cases with $<50 \%$ MSLN distribution and $\geq 50 \%$ of either CA125 or WT1 distribution. Cases without any antigen distribution $\geq 50 \%$ have no colored background. The tumors with $\geq 50 \%$ WT1distribution and $<50 \%$ MSLN distribution. The 269 pie graphs were divided into four groups-non-pleomorphic epithelioid, pleomorphic epithelioid, biphasic, and sarcomatoid - and sorted by MSLN distribution for tumors with MSLN distribution $\geq 50 \%$, followed by WT1 distribution in tumors with MSLN distribution $<50 \%$. In non-pleomorphic epithelioid MPM cases ( $\mathrm{n}=185$ ), $87 \%$ had $\geq 50 \%$ MSLN distribution and $97 \%$ had $\geq 50 \%$ distribution of any single antigen. In pleomorphic epithelioid MPM cases ( $\mathrm{n}=35$ ), $69 \%$ had $\geq 50 \%$ MSLN distribution and $77 \%$ had $\geq 50 \%$ distribution of any single antigen. In biphasic MPM cases $(n=26), 35 \%$ had $\geq 50 \%$ MSLN distribution and $65 \%$ had $\geq 50 \%$ distribution of any single antigen. In sarcomatoid MPM cases $(\mathrm{n}=23), 13 \%$ had $\geq 50 \%$ MSLN distribution and $43 \%$ had $\geq 50 \%$ distribution of any single antigen. 
In conclusion, more than two-thirds of MPM patients have $\geq 50 \%$ distribution of MSLN-positive cells within whole tumor cells and, among the remaining onethird, half have $\geq 50 \%$ distribution of WT1-positive cells. CA125/MSLN coexpression was observed in more than two-thirds of epithelioid and one-third of non-epithelioid MPM patients. These results provide the rationale for developing personalized immunotherapeutic strategies for MPM patients that target these three cancer-associated antigens.

\section{MATERIALS AND METHODS}

\section{Patients}

The current retrospective study was approved by the Institutional Review Board (WA-0436-10) of Memorial Sloan Kettering Cancer Center (MSK). We reviewed all 620 patients who were diagnosed with MPM at MSK between 1989 and 2010. From this cohort, we reviewed 395 MPM cases with available hematoxylin and eosin (H\&E)-stained slides. All slides were re-reviewed by two pathologists; this yielded 301 epithelioid, 59 biphasic, and 35 sarcomatoid MPM cases. Of these, 283 had tumor blocks available for construction of TMAs. Clinical data were collected from the prospectively maintained MPM database.

\section{Histologic evaluation}

Histologic evaluation was performed using an Olympus BX51 microscope (Olympus, Tokyo, Japan) with a standard 22-mm diameter eyepiece. All tumors were classified as either epithelioid, sarcomatoid, or biphasic according to the 2015 World Health Organization classification [48]. For epithelioid mesothelioma, when cytologic pleomorphisms accounted for $\geq 10 \%$ of the tumor they were classified as a pleomorphic subtype [47].

\section{Tissue microarray}

Formalin-fixed, paraffin-embedded tumor blocks were used for construction of TMAs. For epithelioid tumors, six to nine representative tumor areas were marked on H\&E-stained slides. For biphasic tumors, six tumor areas were selected from a predominantly morphologic sarcomatoid lesion. Cylindrical $0.6 \mathrm{~mm}$ tissue cores were arrayed from the marked areas of corresponding paraffin blocks onto a recipient block using an automated tissue arrayer (ATA-27; Beecher Instruments, Sun Prairie, WI); this resulted in five TMA blocks.

\section{Sequential immunohistochemical analysis}

Sequential paraffin $4 \mu \mathrm{m}$-thick sections were cut from the TMA blocks and deparaffinized. Sections were stained using a Ventana Discovery XT automated immunohistochemical stainer (Ventana, Tucson, AZ) for MSLN (5B2, MAb, Vector; diluted at 1:50) [21, 23], CA125 (OC125, MAb, Ventana; pre-diluted) [49], and WT1 (C19, PAb, Santa Cruz; diluted at 1:2000) [50] for IHC analysis. Cell conditioning solution (CC1) standard was used for heat-induced epitope retrieval for $60 \mathrm{~min}$. Then, the slides were incubated by the biotinylated a-mouse secondary for MSLN and CA125 (Vector, diluted at 1:200), and a-rabbit secondary for WT1 (Vector, diluted at 1:200) for $60 \mathrm{~min}$. The Ventana DAB MAP was used for visualization.

CA125 and MSLN expressions were mainly observed in the membrane of tumor cells and WT1 expression was observed in the nucleus. We evaluated the overexpression of these antigens by intensity of antigen expression and distribution of positive cells. The intensity of antigen expression for each core was determined by the pathologist as follows: 0 for no expression; 1 for weak; 2 for moderate; and 3 for strong. The intensity scores of six cores for each patient were averaged and rounded up to the next integer to obtain a mean intensity grade for each patient: 0 for no expression; 1 for weak; 2 for moderate; and 3 for strong. The distribution of antigen-expressing positive cells was determined as a percentage of the total number of cells, which is estimated in $10 \%$ increments. The antigen distribution of six cores for each patient was calculated and rounded up to the next $10 \%$ increment (i.e., a mean distribution score of 1-10\% was assigned a distribution of " $10 \% "$ ").

\section{Author contributions}

T.E., K.K., and W.D.T. collected, analyzed, and interpreted data.

V.W.R. and W.D.T. provided patient materials.

P.S.A. designed the study, and collected, analyzed, and interpreted data.

P.S.A. provided materials and financial support for this study.

T.E. and P.S.A. developed the first draft of the manuscript.

All authors contributed to revising the manuscript and provided final approval to submit for publication.

P.S.A. (corresponding author) had full access to all the data in the study and had final responsibility for the decision to submit for publication.

\section{ACKNOWLEDGMENTS}

We thank Irina Linkov of the MSK Pathology Core Facility for technical assistance with immunohistochemistry. We thank Alex Torres of the MSK Thoracic Surgery Service for his editorial assistance.

\section{CONFLICTS OF INTEREST}

The authors have no conflicts of interest to disclose. 


\section{FUNDING}

The author's laboratory work is supported by the U.S. Department of Defense (BC132124 and LC160212); the National Institutes of Health (P30 CA00874); the Mesothelioma Applied Research Foundation; the Baker Street Foundation; the Derfner Foundation; the Joanne and John DallePezze Foundation; Edythe Griffinger Fellowship Program in Basic Science; and the Mr. William H. Goodwin and Alice Goodwin, the Commonwealth Foundation for Cancer Research, and the Experimental Therapeutics Center.

\section{REFERENCES}

1. Robinson BW, Musk AW, Lake RA. Malignant mesothelioma. Lancet. 2005; 366:397-408.

2. Van Schil PE, Baas P, Gaafar R, Maat AP, Van de Pol M, Hasan B, Klomp HM, Abdelrahman AM, Welch J, van Meerbeeck JP. Trimodality therapy for malignant pleural mesothelioma: results from an EORTC phase II multicentre trial. Eur Respir J. 2010; 36:1362-1369.

3. Krug LM, Pass HI, Rusch VW, Kindler HL, Sugarbaker DJ, Rosenzweig KE, Flores R, Friedberg JS, Pisters K, Monberg M, Obasaju CK, Vogelzang NJ. Multicenter phase II trial of neoadjuvant pemetrexed plus cisplatin followed by extrapleural pneumonectomy and radiation for malignant pleural mesothelioma. J Clin Oncol. 2009; 27:3007-3013.

4. de Perrot M, Feld R, Leighl NB, Hope A, Waddell TK, Keshavjee S, Cho BC. Accelerated hemithoracic radiation followed by extrapleural pneumonectomy for malignant pleural mesothelioma. J Thorac Cardiovasc Surg. 2016; 151:468-473.

5. Rimner A, Zauderer MG, Gomez DR, Adusumilli PS, Parhar PK, Wu AJ, Woo KM, Shen R, Ginsberg MS, Yorke ED, Rice DC, Tsao AS, Rosenzweig KE, et al. Phase II Study of Hemithoracic Intensity-Modulated Pleural Radiation Therapy (IMPRINT) As Part of Lung-Sparing Multimodality Therapy in Patients With Malignant Pleural Mesothelioma. J Clin Oncol. 2016; 34:2761-8.

6. Weder W, Stahel RA, Bernhard J, Bodis S, Vogt P, Ballabeni P, Lardinois D, Betticher D, Schmid R, Stupp R, Ris HB, Jermann M, Mingrone W, et al. Multicenter trial of neo-adjuvant chemotherapy followed by extrapleural pneumonectomy in malignant pleural mesothelioma. Ann Oncol. 2007; 18:1196-1202.

7. Treasure T, Lang-Lazdunski L, Waller D, Bliss JM, Tan C, Entwisle J, Snee M, O’Brien M, Thomas G, Senan S, O’Byrne K, Kilburn LS, Spicer J, et al. Extra-pleural pneumonectomy versus no extra-pleural pneumonectomy for patients with malignant pleural mesothelioma: clinical outcomes of the Mesothelioma and Radical Surgery (MARS) randomised feasibility study. Lancet Oncol. 2011; 12:763-772.
8. Stahel RA, Riesterer O, Xyrafas A, Opitz I, Beyeler M, Ochsenbein A, Fruh M, Cathomas R, Nackaerts K, Peters S, Mamot C, Zippelius A, Mordasini C, et al. Neoadjuvant chemotherapy and extrapleural pneumonectomy of malignant pleural mesothelioma with or without hemithoracic radiotherapy (SAKK 17/04): a randomised, international, multicentre phase 2 trial. Lancet Oncol. 2015; 16:1651-1658.

9. Treasure T. What is the best approach for surgery of malignant pleural mesothelioma? It is to put our efforts into obtaining trustworthy evidence for practice. J Thorac Cardiovasc Surg. 2016; 151:307-309.

10. Bueno R, Stawiski EW, Goldstein LD, Durinck S, De Rienzo A, Modrusan Z, Gnad F, Nguyen TT, Jaiswal BS, Chirieac LR, Sciaranghella D, Dao N, Gustafson CE, et al. Comprehensive genomic analysis of malignant pleural mesothelioma identifies recurrent mutations, gene fusions and splicing alterations. Nat Genet. 2016; 48:407-416.

11. Bonelli MA, Fumarola C, Monica S, Alfieri R. New therapeutic strategies for malignant pleural mesothelioma. Biochem Pharmacol. 2016; 123:8-18.

12. Anraku M, Cunningham KS, Yun Z, Tsao MS, Zhang L, Keshavjee S, Johnston MR, de Perrot M. Impact of tumorinfiltrating $\mathrm{T}$ cells on survival in patients with malignant pleural mesothelioma. J Thorac Cardiovasc Surg. 2008; 135:823-829.

13. Yamada N, Oizumi S, Kikuchi E, Shinagawa N, KonishiSakakibara J, Ishimine A, Aoe K, Gemba K, Kishimoto T, Torigoe T, Nishimura M. CD8+ tumor-infiltrating lymphocytes predict favorable prognosis in malignant pleural mesothelioma after resection. Cancer Immunol Immunother. 2010; 59:1543-1549.

14. Ujiie H, Kadota K, Nitadori JI, Aerts JG, Woo KM, Sima CS, Travis WD, Jones DR, Krug LM, Adusumilli PS. The tumoral and stromal immune microenvironment in malignant pleural mesothelioma: A comprehensive analysis reveals prognostic immune markers. Oncoimmunology. 2015; 4:e1009285.

15. Cornelissen R, Lievense LA, Maat AP, Hendriks RW, Hoogsteden HC, Bogers AJ, Hegmans JP, Aerts JG. Ratio of intratumoral macrophage phenotypes is a prognostic factor in epithelioid malignant pleural mesothelioma. PLoS One. 2014; 9:e106742.

16. Hassan R, Miller AC, Sharon E, Thomas A, Reynolds JC, Ling A, Kreitman RJ, Miettinen MM, Steinberg SM, Fowler DH, Pastan I. Major cancer regressions in mesothelioma after treatment with an anti-mesothelin immunotoxin and immune suppression. Sci Transl Med. 2013; 5:208ra147.

17. Adusumilli PS, Cherkassky L, Villena-Vargas J, Colovos C, Servais E, Plotkin J, Jones DR, Sadelain M. Regional delivery of mesothelin-targeted CAR $\mathrm{T}$ cell therapy generates potent and long-lasting CD4-dependent tumor immunity. Sci Transl Med. 2014; 6:261ra151.

18. Sadelain M, Brentjens R, Riviere I. The basic principles of chimeric antigen receptor design. Cancer Discov. 2013; 3:388-398. 
19. Fedorov VD, Sadelain M, Kloss CC. Novel approaches to enhance the specificity and safety of engineered $\mathrm{T}$ cells. Cancer J. 2014; 20:160-165.

20. Morello A, Sadelain M, Adusumilli PS. MesothelinTargeted CARs: Driving T Cells to Solid Tumors. Cancer Discov. 2015; 6:133-46.

21. Kachala SS, Bograd AJ, Villena-Vargas J, Suzuki K, Servais EL, Kadota K, Chou J, Sima CS, Vertes E, Rusch VW, Travis WD, Sadelain M, Adusumilli PS. Mesothelin overexpression is a marker of tumor aggressiveness and is associated with reduced recurrence-free and overall survival in early-stage lung adenocarcinoma. Clin Cancer Res. 2014; 20:1020-1028.

22. Rizk NP, Servais EL, Tang LH, Sima CS, Gerdes H, Fleisher M, Rusch VW, Adusumilli PS. Tissue and serum mesothelin are potential markers of neoplastic progression in Barrett's associated esophageal adenocarcinoma. Cancer Epidemiol Biomarkers Prev. 2012; 21:482-486.

23. Servais EL, Colovos C, Rodriguez L, Bograd AJ, Nitadori J, Sima C, Rusch VW, Sadelain M, Adusumilli PS. Mesothelin overexpression promotes mesothelioma cell invasion and MMP-9 secretion in an orthotopic mouse model and in epithelioid pleural mesothelioma patients. Clin Cancer Res. 2012; 18:2478-2489.

24. Tozbikian G, Brogi E, Kadota K, Catalano J, Akram M, Patil S, Ho AY, Reis-Filho JS, Weigelt B, Norton L, Adusumilli PS, Wen HY. Mesothelin expression in triple negative breast carcinomas correlates significantly with basal-like phenotype, distant metastases and decreased survival. PLoS One. 2014; 9:e114900.

25. Haridas D, Chakraborty S, Ponnusamy MP, Lakshmanan I, Rachagani S, Cruz E, Kumar S, Das S, Lele SM, Anderson JM, Wittel UA, Hollingsworth MA, Batra SK. Pathobiological implications of MUC16 expression in pancreatic cancer. PLoS One. 2011; 6:e26839.

26. Kushitani K, Takeshima Y, Amatya VJ, Furonaka O, Sakatani A, Inai K. Immunohistochemical marker panels for distinguishing between epithelioid mesothelioma and lung adenocarcinoma. Pathol Int. 2007; 57:190-199.

27. Cedres S, Nunez I, Longo M, Martinez P, Checa E, Torrejon D, Felip E. Serum tumor markers CEA, CYFRA21-1, and CA-125 are associated with worse prognosis in advanced non-small-cell lung cancer (NSCLC). Clin Lung Cancer. 2011; 12:172-179.

28. Rump A, Morikawa Y, Tanaka M, Minami S, Umesaki N, Takeuchi M, Miyajima A. Binding of ovarian cancer antigen CA125/MUC16 to mesothelin mediates cell adhesion. J Biol Chem. 2004; 279:9190-9198.

29. Gubbels JA, Belisle J, Onda M, Rancourt C, Migneault M, Ho M, Bera TK, Connor J, Sathyanarayana BK, Lee B, Pastan I, Patankar MS. Mesothelin-MUC16 binding is a high affinity, $\mathrm{N}$-glycan dependent interaction that facilitates peritoneal metastasis of ovarian tumors. Mol Cancer. 2006; 5:50.
30. Shimizu A, Hirono S, Tani M, Kawai M, Okada K, Miyazawa M, Kitahata Y, Nakamura Y, Noda T, Yokoyama S, Yamaue H. Coexpression of MUC16 and mesothelin is related to the invasion process in pancreatic ductal adenocarcinoma. Cancer Sci. 2012; 103:739-746.

31. Chen SH, Hung WC, Wang P, Paul C, Konstantopoulos K. Mesothelin binding to CA125/MUC16 promotes pancreatic cancer cell motility and invasion via MMP-7 activation. Sci Rep. 2013; 3:1870.

32. Le DT, Brockstedt DG, Nir-Paz R, Hampl J, Mathur S, Nemunaitis J, Sterman DH, Hassan R, Lutz E, Moyer B, Giedlin M, Louis JL, Sugar EA, et al. A live-attenuated Listeria vaccine (ANZ-100) and a live-attenuated Listeria vaccine expressing mesothelin (CRS-207) for advanced cancers: phase I studies of safety and immune induction. Clin Cancer Res. 2012; 18:858-868.

33. Thomas AM, Santarsiero LM, Lutz ER, Armstrong TD, Chen YC, Huang LQ, Laheru DA, Goggins M, Hruban RH, Jaffee EM. Mesothelin-specific CD8(+) T cell responses provide evidence of in vivo cross-priming by antigenpresenting cells in vaccinated pancreatic cancer patients. $\mathrm{J}$ Exp Med. 2004; 200:297-306.

34. Reinartz S, Hombach A, Kohler S, Schlebusch H, Wallwiener D, Abken H, Wagner U. Interleukin-6 fused to an anti-idiotype antibody in a vaccine increases the specific humoral immune response against CA125+ (MUC-16) ovarian cancer. Cancer Res. 2003; 63:3234-3240.

35. Hassan R, Ebel W, Routhier EL, Patel R, Kline JB, Zhang J, Chao Q, Jacob S, Turchin H, Gibbs L, Phillips MD, Mudali $\mathrm{S}$, Iacobuzio-Donahue $\mathrm{C}$, et al. Preclinical evaluation of MORAb-009, a chimeric antibody targeting tumorassociated mesothelin. Cancer Imm. 2007; 7:20.

36. Hassan R, Kindler HL, Jahan T, Bazhenova L, Reck M, Thomas A, Pastan I, Parno J, O'Shannessy DJ, Fatato P, Maltzman JD, Wallin BA. Phase II clinical trial of amatuximab, a chimeric antimesothelin antibody with pemetrexed and cisplatin in advanced unresectable pleural mesothelioma. Clin Cancer Res. 2014; 20:5927-5936.

37. Hassan R, Sharon E, Thomas A, Zhang J, Ling A, Miettinen M, Kreitman RJ, Steinberg SM, Hollevoet K, Pastan I. Phase 1 study of the antimesothelin immunotoxin SS1P in combination with pemetrexed and cisplatin for frontline therapy of pleural mesothelioma and correlation of tumor response with serum mesothelin, megakaryocyte potentiating factor, and cancer antigen 125. Cancer. 2014; 20:3311-9.

38. Keilholz U, Menssen HD, Gaiger A, Menke A, Oji Y, Oka Y, Scheibenbogen C, Stauss H, Thiel E, Sugiyama H. Wilms' tumour gene 1 (WT1) in human neoplasia. Leukemia. 2005; 19:1318-1323.

39. Amin KM, Litzky LA, Smythe WR, Mooney AM, Morris JM, Mews DJ, Pass HI, Kari C, Rodeck U, Rauscher FJ 3rd, Kaiser LR, Albelda SM. Wilms' tumor 1 susceptibility 
(WT1) gene products are selectively expressed in malignant mesothelioma. Am J Pathol. 1995; 146:344-356.

40. Kumar-Singh S, Segers K, Rodeck U, Backhovens H, Bogers J, Weyler J, Van Broeckhoven C, Van Marck E. WT1 mutation in malignant mesothelioma and WT1 immunoreactivity in relation to p53 and growth factor receptor expression, cell-type transition, and prognosis. J Pathol. 1997; 181:67-74.

41. Krug LM, Dao T, Brown AB, Maslak P, Travis W, Bekele S, Korontsvit T, Zakhaleva V, Wolchok J, Yuan J, Li H, Tyson L, Scheinberg DA. WT1 peptide vaccinations induce CD4 and CD8 $\mathrm{T}$ cell immune responses in patients with mesothelioma and non-small cell lung cancer. Cancer Immunol Immunother. 2010; 59:1467-1479.

42. Zauderer M, Dao T, Rusch V, Ginsberg M, Tsao A, Panageas K, Stergiou A, Scheiberg D, Krug L. Randomized phase II study of adjuvant WT1 vaccine (SLS-001) for malignant pleural mesothelioma (MPM) after multimodality therapy. J Clin Oncol. 2016; 34:abstr 8519.

43. Genssler S, Burger MC, Zhang C, Oelsner S, Mildenberger I, Wagner M, Steinbach JP, Wels WS. Dual targeting of glioblastoma with chimeric antigen receptor-engineered natural killer cells overcomes heterogeneity of target antigen expression and enhances antitumor activity and survival. Oncoimmunol. 2016; 5:e1119354.

44. Hegde M, Corder A, Chow KK, Mukherjee M, Ashoori A, Kew Y, Zhang YJ, Baskin DS, Merchant FA, Brawley VS, Byrd TT, Krebs S, Wu MF, et al. Combinational targeting offsets antigen escape and enhances effector functions of adoptively transferred $\mathrm{T}$ cells in glioblastoma. Mol Ther. 2013; 21:2087-2101.
45. Hegde M, Mukherjee M, Grada Z, Pignata A, Landi D, Navai SA, Wakefield A, Fousek K, Bielamowicz K, Chow KK, Brawley VS, Byrd TT, Krebs S, et al. Tandem CAR $\mathrm{T}$ cells targeting HER2 and IL13Ralpha2 mitigate tumor antigen escape. J Clin Invest. 2016; 126:3036-3052.

46. Rusch VW, Giroux D, Kennedy C, Ruffini E, Cangir AK, Rice D, Pass H, Asamura H, Waller D, Edwards J, Weder W, Hoffmann H, van Meerbeeck JP. Initial Analysis of the International Association For the Study of Lung Cancer Mesothelioma Database. J Thorac Oncol. 2012; 7:1631-1639.

47. Kadota K, Suzuki K, Sima CS, Rusch VW, Adusumilli PS, Travis WD. Pleomorphic epithelioid diffuse malignant pleural mesothelioma: a clinicopathological review and conceptual proposal to reclassify as biphasic or sarcomatoid mesothelioma. J Thorac Oncol. 2011; 6:896-904.

48. Travis WD, Brambilla E, Burke AP, Marx A, Nicholson AG. World Health Organization Classification of Tumours of the Lung, Pleura, Thymus and Heart. Lyon, France: IARC Press; 2015.

49. Dharma Rao T, Park KJ, Smith-Jones P, Iasonos A, Linkov I, Soslow RA, Spriggs DR. Novel monoclonal antibodies against the proximal (carboxy-terminal) portions of MUC16. Appl Immunohistochem Mol Morphol. 2010; 18:462-472.

50. Dupont J, Wang X, Marshall DS, Leitao M, Hedvat CV, Hummer A, Thaler H, O'Reilly RJ, Soslow RA. Wilms Tumor Gene (WT1) and p53 expression in endometrial carcinomas: a study of 130 cases using a tissue microarray. Gynecol Oncol. 2004; 94:449-455. 